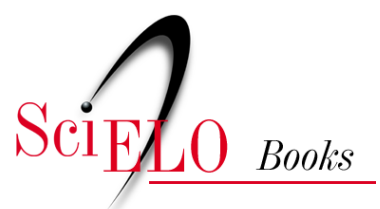

\title{
Apresentação Abrindo Cancelas
}

Tania Bacelar de Araujo

\section{SciELO Books / SciELO Livros / SciELO Libros}

ARAUJO, T. B. Apresentação - Abrindo Cancelas. In: SOUSA, C. M., THEIS, I. M., and BARBOSA, J. L. A., eds. Celso Furtado: a esperança militante (Desafios): vol. 3 [online]. Campina Grande: EDUEPB, 2020, pp. 15-19. Projeto editorial 100 anos de Celso Furtado collection, vol. 3. ISBN: 978-65-86221-12-1. https://doi.org/10.7476/9786586221688.0001.

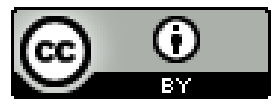

All the contents of this work, except where otherwise noted, is licensed under a Creative Commons Attribution 4.0 International license.

Todo o conteúdo deste trabalho, exceto quando houver ressalva, é publicado sob a licença Creative Commons Atribição 4.0.

Todo el contenido de esta obra, excepto donde se indique lo contrario, está bajo licencia de la licencia Creative Commons Reconocimento 4.0. 


\section{Apresentação}

\section{Abrindo cancelas ${ }^{1}$}

Tania Bacelar de Araujo²

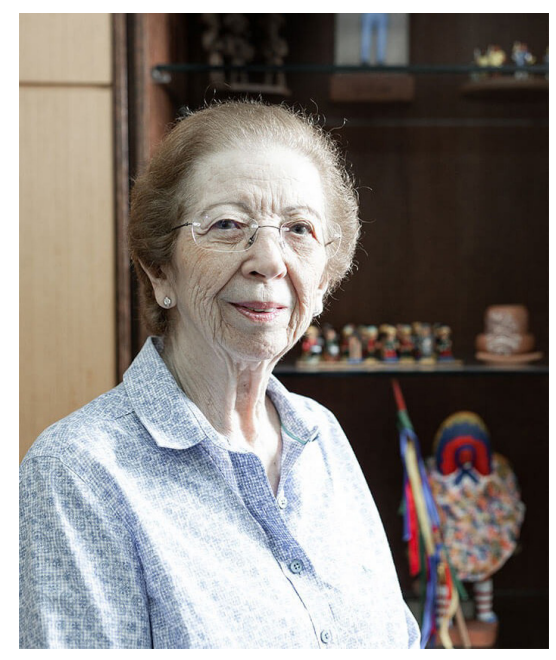

Centenário de nascimento de Celso Furtado ensejou muiTAS iniciativas, e isso foi muito importante, dada a contribuição deste ilustre brasileiro e seu exemplo como pensador que transformava reflexão em ação, sobretudo considerando o momento vivido pelo Brasil: a democracia sob constante ameaça e a economia imersa em crise estrutural, experimentando inusitada crise conjuntural provocada pela pandemia, tornando dramático o nosso quadro social.

1 Texto elaborado a partir da palestra de abertura do Seminário Virtual Centenário de Celso Furtado, no dia 26 de julho de 2020, que marcou, também, o lançamento do Volume 3 da Trilogia Celso Furtado: a esperança militante (Desafios). Vídeo disponível em: https://www.youtube.com/watch?v=tWYo9T5cJ_o\&t=8584s

2 Economista pela UNICAP, Socióloga pela Fafire, Mestre e Doutora em Economia pela Universidade de Paris I Panthéon-Sorbonne. É professora Emérita da UFPE. Foi diretora da Sudene e da Fundaj, Secretária de Planejamento e da Fazenda do Estado de Pernambuco, Secretária de Políticas de Desenvolvimento Regional do Ministério da Integração Nacional e Secretária de Planejamento da Prefeitura do Recife. 
Nesse contexto, merece referência especial a trilogia organizada pela Universidade Estadual da Paraíba (UEPB), Universidade Pública de um estado nordestino, justo a Paraíba, que, por conta da visão preconceituosa sobre nossa região, se transformou, recentemente, em sinônimo do Nordeste, no nosso grito uníssono: somos todos paraibanos! Trilogia que, entendo, ficará registrada na história como a mais importante homenagem entre todas que este centenário estimulou.

O grande objetivo da trilogia, da qual participei com muita honra, é o de homenagear, com reflexões de pessoas de diversas formações e visões, o centenário do nascimento deste grande brasileiro, Celso Monteiro Furtado, que dedicou sua vida a tentar entender e explicar o Brasil (que país é esse?), para propor estratégias e iniciativas que pudessem ajudar a transformar nosso pais, consolidando-o como uma verdadeira nação.

Dentre outras iniciativas semelhantes, destaco a da Associação Brasileira de Economistas pela Democracia (ABED), que também mobilizou muita gente para produzir a coletânea Celso Furtado: as lutas de um economista ${ }^{3}$, lançada no mesmo dia do nascimento do ilustre homenageado.

É estimulante ver reconhecido, como economista, alguém que, sempre valorizando a importância da economia na vida dos povos, nos ensinou que a dimensão econômica é apenas uma das dimensões da vida social. E que o agente econômico não é apenas um ente que toma decisões econômicas racionais - abstração exaltada por certas visões - mas, igualmente, um agente político e um ator social, que age influenciado pela cultura do ambiente onde atua, e que constrói elo fundamental da relação sociedade $x$ natureza.

Saído do sertão paraibano para o mundo, era um verdadeiro cientista: apoiava-se em teorias sólidas, conceitos claros, procedimentos cuidadosos, colocando-os sempre em diálogo com a realidade e, por isso, era capaz de revisitá-los e fazer avançar ideias, teses, interpretações e, especialmente, chegar a proposições para atuar na realidade. Quando se examina sua obra sobre o desenvolvimento - seu objeto central de preocupação - percebe-se que ele vai refinando e ampliando sua visão, sendo,

3 QUinTela, A.; GAlVÃO, A. C. F.; BOlaño, C.; PATRÍCIO, I.; MANZANO, M.; MACEDO, M. M.; LE COCQ, NELSON (ORGs). Celso Furtado: os combates de um economista. São Paulo: Fundação Perseu Abramo: Expressão Popular, 2020. Disponível em: https://fpabramo.org.br/publicacoes/wp-content/uploads/ sites/5/2020/o7/Celso-Furtado-Os-combates-de-um-economista_WEBFINAL3.pdf 
a meu ver, precursor da concepção contemporânea de desenvolvimento sustentável.

Para Furtado, desenvolvimento deve ser entendido como um processo de transformação que não se mede apenas pelo tamanho ou ritmo de crescimento do PIB, mas pelas condições de vida das pessoas, pela riqueza da vida cultural da sociedade, pela qualidade do ambiente institucional (no qual a democracia é fundamental) e pelo grau de interação saudável com a natureza.

Basta ler "O mito do desenvolvimento" para vê-lo, nos anos 1970, reafirmando a importância da dimensão social e ambiental, ou revisitar seu livro "Criatividade e dependência na civilização industrial", publicado no limiar dos anos 1980, para entender a importância que atribui à dimensão política e à autonomia cultural na vida de uma nação que se quer "desenvolvida" (aliás, ao ler este livro se entende porque foi Ministro da Cultura do Brasil).

Essa visão ampla alimentava seu desejo de transformar a realidade, em particular, a brasileira e, em especial, a nordestina.

E, embora tendo percebido a encalacrada em que nos metemos desde os anos 1980, e escreva um alerta nos anos 1990 no livro "Brasil: a construção interrompida”, prenúncio do que hoje vivemos, nunca deixou fechada a possibilidade de transformar para melhor a dura realidade brasileira.

Este livro traz, em um parágrafo denso, uma síntese de nossa trajetória, e um alerta:

\begin{abstract}
"Em meio milênio de história, partindo de uma constelação de feitorias, de populações indígenas desgarradas, de escravos transplantados de outro continente, de aventureiros europeus e asiáticos em busca de um destino melhor, chegamos a um povo de extraordinária polivalência cultural, a um país sem paralelo pela vastidão territorial e homogeneidade linguística e religiosa. Mas nos falta a experiência de provas cruciais como as que conheceram outros povos cuja sobrevivência chegou a ser ameaçada. E nos falta, também, um verdadeiro conhecimento de nossas possibilidades e, principalmente, de nossas debilidades. Mas não ignoremos que o tempo histórico se acelera, e que a contagem desse tempo se faz contra nós". ${ }^{4}$
\end{abstract}

Furtado sabia das travas de nossas heranças, mas tinha plena consciência de nossas potencialidades. Pressentia a dimensão da ruptura que vinha se dando nos padrões técnicos à escala mundial, no bojo da

4 FURTADO, C. Brasil: a construção interrompida. Rio de Janeiro, Editora Paz e Terra, 1992, 87p. 
revolução cientifico-tecnológica que se firmaria no século XXI, e nos estimularia a refletir sobre novas estratégias de desenvolvimento. Porque, como sertanejo, não desconhece a força bruta dos poderosos, mas não teme desafios e busca sempre resistir e se reinventar.

A melhor forma, portanto, de homenagearCelso Furtadoéesta:assumir a essência do povo nordestino e manter firme a disposição para construir novas estratégias de atuação e novas utopias possíveis. Homenageá-lo é continuar a disputa pela construção de um mundo melhor e insistir que o Brasil pode ser uma verdadeira nação, quando despertarmos seus potenciais latentes, um dos quais é a identidade nacional, construída na multifacetada base popular, que se expressa na nossa polivalência cultural.

As elites colonizadas não sabem o que é isso, como dizia outro paraibano ilustre: Ariano Suassuna, que fazia parte dos brasileiros que nunca foram à Disney, para espanto de uma dondoca carioca.

Não esqueçamos, também, que o Nordeste é um dos berços da nação brasileira. Lugar que Furtado, ao ver o resultado da modernização conservadora, acelerada no período em que ficou exilado, afirmou que continuava sendo síntese do Brasil: "O Nordeste é o espelho onde a imagem do Brasil se reflete com brutal nitidez". ${ }^{5}$ Este Nordeste que, hoje, em nome do Brasil, o homenageia.

Celso Furtado era alguém que - como disse o professor Cidoval Sousa, referindo-se à entrevista de José Otamar de Carvalho, constante do Volume 2 desta trilogia - "abria cancelas". ${ }^{6}$ Aquelas que fechavam acesso às estradas, à água - em pleno momento de seca - e à terra para plantar com autonomia, no interior paraibano e nordestino.

Cancelas, porém, que não conseguem bloquear a esperança e a determinação de muitos...

Algumas cancelas foram abertas, mas surgiram novas. E precisamos de faróis como a visão deixada por ele para identificá-las e construir maneiras de abri-las.

5 BACELAR, T. Revisitando a Questão Regional, in: Cadernos do Desenvolvimento, n. 1, Centro Internacional Celso Furtado de Políticas para o Desenvolvimento, Rio de Janeiro, 2006. Disponível em: http://www. cadernosdodesenvolvimento.org.br/ojs-2.4.8/index.php/cdes/article/ view/329/308

6 SOUSA, C.M.; THEIS, I. M.; ALBINO, J..L.B. Celso Furtado: a esperança militante (depoimentos). Campina Grande (PB): EDUEPB/UNIÃO, 2020. Disponível: http:// www.uepb.edu.br/download/documentos/documentos_2020/Celso-Furtado-Aesperanca-militante-Volume-2.pd 
Olhar para a frente, identificando desafios herdados e novos, como o fizeram os que contribuíram para este volume 3, ora apresentado. A proposta é buscar intervir no debate contemporâneo sobre o desenvolvimento com novas análises e soluções. E este volume reflete uma das mudanças mais relevantes ocorridas na região nordestina nos anos recentes: a ampliação e interiorização do sistema de ensino superior brasileiro, em especial, o público.

Os artigos deste volume dialogam com diversos pensadores e, de modo particular, com o nosso homenageado, Celso Furtado, a quem aplico a mesma frase que ele usou na despedida de Raul Prebisch da CEPAL, citada por Marcos Formiga, ex-Superintendente da SUDENE e hoje professor da UnB, na sua tese: "Para homens que se projetaram pela inteligência criadora e têm capacidade de influir pela força de suas ideias, não existem despedidas. Eles sempre estarão presentes"?

7 Ver: BACELAR, T. Um intelectual preocupado com a inserção do Brasil na ordem econômica, social e política contemporânea, em Teoria e Debate. Disponível em: https://teoriaedebate.org.br/2005/02/o1/celso-furtado-economista-e-cientista-social/\#: :text=Celso\%2oFurtado\%2C\%2odespedida $\% 2$ ode $\% 2$ oRa $\%$ C3\%BAl, Furtado\%2ofaleceu $\% 2$ oa os $\% 2084 \% 20$ anos.\&text=Em\%201939\%2omudou\%2Dse\%2opara,do\%2oBrasil\%2o(hoje\%2o UFRJ). 